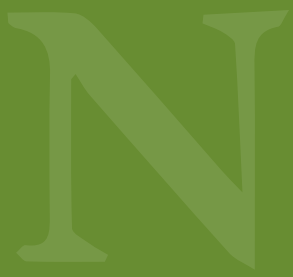

SEccion: Problemas espaciales contemporaneos
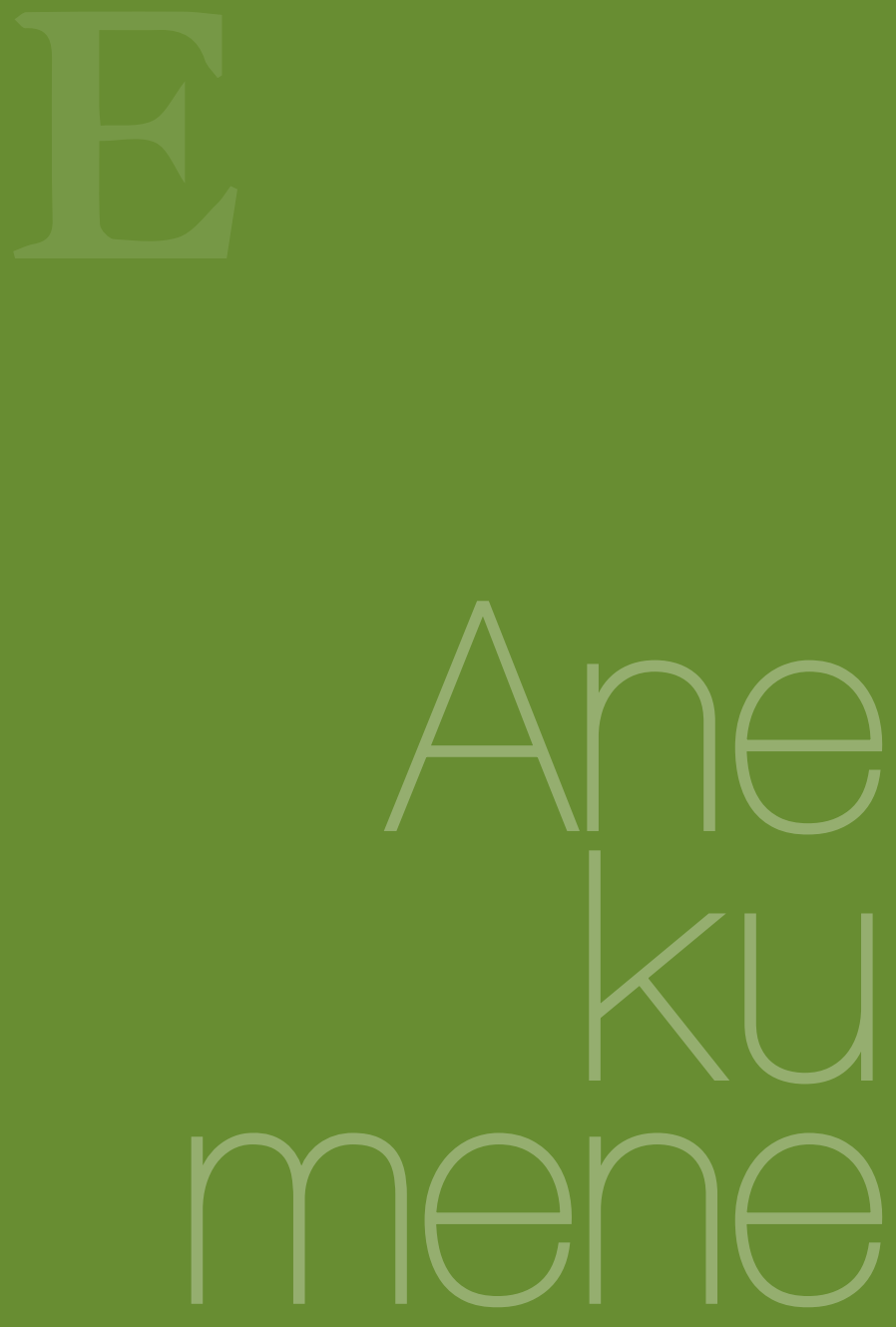


\section{A educação geográfica, aprendizagem e docência no ensino média}

\section{Geographic Education: Learning and Teaching in Middle School \\ La educación geográfica, aprendizaje y docencia en la enseñanza media}

Manoel Martins de Santana Filho*

\begin{abstract}
Resumo
O presente trabalho surge no escopo de uma atividade de pesquisa desenvolvida entre professores da universidade e de uma escola pública municipal de ensino médio no Estado do Rio de Janeiro. Dentre os objetivos, estava a melhoria dos processos de ensino-aprendizagem, na perspectiva de interação entre a Universidade e a Escola Básica, em especial, aqueles conteúdos relacionados ao ensino de geografia. Experimentar novos materiais didáticos, articulados à reflexão da prática pedagógica dos professores de geografia e de novas metodologias de ensino e novos princípios de organização curricular, foi o desafio enfrentado. Nas atividades desenvolvidas buscou-se contribuir para
\end{abstract}

um melhor desempenho da prática docente, ligando teoria e prática. Assim, o foco fundamental do projeto visava explicitar, problematizar e reconstruir a relação conteúdo-método e currículo-didática nas práticas educativas na escola pública, através da proposição e experimentação de diversas situações de aprendizagem de conteúdos escolares baseadas na metodologia de problematização da prática social dos alunos.

\section{Palavras-chave}

didática da geografia; educação secundária; geografia escolar; processos formativos.

* Profesor de la Universidade Federal Fluminense. 


\begin{abstract}
The present work arises in the frame of an activity of investigation developed between university teachers and one public municipal school of middle teaching in the State of Rio de Janeiro. Between the proposed aims one finds the improvement of the processes of education - learning, in the perspective of interaction between the University and the Basic School, specially of those contents related to the education of the geography. To experience new didactic materials articulated to the reflection of the pedagogic practice of the teachers and of new methodologies and principles of curricular organization, principal challenge faced during the investigative route. In the developed activities it was sought to
\end{abstract}

\section{Resumen}

El presente trabajo surge en el marco de una actividad de investigación desarrollada entre profesores universitarios y de una escuela pública municipal de enseñanza media en el Estado de Río de Janeiro. Entre los objetivos propuestos se encuentra la mejora de los procesos de enseñanza-aprendizaje, en la perspectiva de interacción entre la Universidad y la Escuela Básica, especialmente de aquellos contenidos relacionados con la enseñanza de la geografía. Experimentar nuevos materiales didácticos, articulados a la reflexión de la práctica pedagógica de los profesores y de nuevas metodologías y principios de organización curricular, fue el desafío principal enfrentado durante el recorrido investigativo. En las actividades desarrolladas se buscó contribuir contribute to a better performance of the educational work, tying theory and practice of a substantial way. This way, the fundamental area of the project was trying specify, make an issue and to reconstruct the relation content - method and curriculum - didactics in the educational practices of the public school from the proposition and experimentation of diverse situations of learning based on the methodology of make problematic the social practice of the students.

\section{Keywords}

Geography's didactics, Middle school, school geography, formative processes a un mejor desempeño del quehacer docente, ligando teoría y práctica de manera sustancial. Así, el foco fundamental del proyecto pretendía explicitar, problematizar y reconstruir la relación contenido-método y currículo-didáctica en las prácticas educativas de la escuela pública a partir de la proposición y experimentación de diversas situaciones de aprendizaje basadas en la metodología de problematización de la práctica social de los alumnos.

\section{Palabras clave}

didáctica de la geografía; enseñanza media; geografía escolar; procesos formativos. 


\section{Introdução}

O presente trabalho resulta das reflexões oriundas de projeto desenvolvido em parceria com uma escola pública de educação básica que reuniu, em distintos momentos e condições, educadores da universidade e da educação básica, bem como licenciandos e estudantes do ensino médio.

Ainda que a proposta original do projeto tenha se desenvolvido em torno do escopo proposto no edital público voltado para a melhoria do ensino nas escolas públicas do Estado do Rio de Janeiro ${ }^{1}$, daquela experiência resultou um conjunto de aprendizados, constatações e exercício reflexivo que vem ganhando desdobramentos em nossa experiência formadora e formativa. Além das atividades didáticas e do tratamento dos conteúdos; da produção de recursos didáticos - que foram objeto de atenção e ação da equipe; da organização da escola em torno dos recursos mobilizados, a reflexão sobre a docência e as experiências formativas em muito nos alertou para a necessidade de melhor desenvolvê-las. Então, orientados pela perspectiva de autoria inspirada em Benjamin e estimulando a construção de narrativas é que encontramos potencial para o promover a autoria docente (ao menos em um estágio inicial).

Inicialmente, buscou-se conhecer as ações docentes promovidas na escola a partir das informações prestadas pelas professoras de Geografia em torno de seus conhecimentos sobre o currículo, o uso de materiais didáticos, as suas estratégias em torno dos conteúdos e da relação com os estudantes. Dessa etapa conhecemos o seguinte com as respostas das professoras: as três professoras tiveram formação em instituições públicas e particulares; uma possuía mais de 20 anos de experiências e as demais menos de cinco anos; todas trabalhavam com um volume de trabalho que envolvia entre 6 e 12 turmas de educação básica; quanto aos procedimentos todas experimentavam diversas práticas além das aulas expositivas (jogos, debates, seminários, audiovisuais etc.); o volume de leitura declarado por elas ficou entre 5 e 10 livros em um ano, sendo que apenas uma indicou leituras de lazer; o documento curricular da rede municipal não era de conhecimento explícito por nenhuma delas, dado que o mesmo não teria sido divulgado aos educadores; a adaptação do currículo da escola esbarrava na pouca participação dos professores; o livro utilizado por elas era considerado inadequado ao trabalho desenvolvido naquela escola, pois não teriam recebido o que fora escolhido; todas apontaram como dificuldade os poucos recursos para o trabalho diário com os alunos; os conceitos geográficos e noções território, lugar, organização espacial, localização, cartografia, globalização, paisagem, região, escala, coordenadas geográficas e fuso horários foram citados por elas como aqueles que mais orientavam os seus trabalhos em sala de aula; os recursos avaliativos adotados eram os registros escritos

1 Trata-se de Edital da Fundação de Amparo à Pesquisa do Estado do Rio de Janeiro (FAPERJ) que está definido como "Apoio à Melhoria do Ensino em Escolas da Rede Pública no Estado do Rio de Janeiro"; Edital FAPERJ 016/2011. (provas, trabalhos diversos) e seminários, sendo que apenas uma declarou considerar elementos atitudinais dos estudantes; para reconhecer se os alunos teriam alcançado um "raciocínio espacial" todas consideravam a capacidade de expressão oral e escrita, bem como formulações elaboradas por eles durantes as discussões sobre paisagens ou sobre os temas objetos das aulas.

Nos momentos seguintes, enquanto se desenvolviam as atividades diversas, dialogávamos com as professoras e com outros profissionais da escola motivados por compreender duas outras funções que, entendíamos, nos colocava em alerta na relação com aqueles educadores: a partir de suas perspectivas atuantes na escola básica, como elas viam a relação com a universidade; outra, a nossa condição de especialista e formador de professores na universidade pública. Estes dois elementos faziam perguntar-me frequentemente: como podemos contribuir com a prática docente de maneira orgânica, comprometida e responsável?

\section{As razões para propor uma experiência compartilhada entre a docência na educação básica e os processos formativos de formação de professores}

Ao longo das atividades do projeto éramos desafiados a pensar sobre as condições da docência, os currículos e as atividades formativas propostas na formação dos licenciandos em Geografia. Então, procuramos provocar que tal experiência pudesse mobilizar as professoras da escola e os licenciandos para enfrentar os desafios de melhor promover a educação geográfica no contexto das atividades e conteúdos desenvolvidos.

Entendíamos que as discussões mais recentes oriundas do avanço das pesquisas e da produção sobre o Ensino de Geografia no Brasil têm trazido contribuições significativas para os cursos de formação de professores e, de certa forma, impactado a produção de material didático. Igualmente, as discussões e debates teóricos-conceituais da ciência geográfica e da educação vêm sendo consideradas nesse contexto. Porém, em diversos relatos e depoimentos de professores regentes e licenciandos ainda se remetiam na insistência na aula conteudista e decoreba, na desarticulação conteúdo-vida cotidiana. Como detectar esse avanço na educação geográfica escolar hoje?

Além dessa razão, já suficiente o bastante para justificar investimento pessoal e coletivo de investigação, tínhamos a responsabilidade de proporcionar aos licenciandos atuantes no projeto a possibilidade de vivenciar os diversos, complexos e contraditórios processos do ambiente escolar (prática pedagógica e prática docente ${ }^{2}$ ). Ou seja, as atividades

2 Aqui adotamos a compreensão de prática docente e prática pedagógica expressa em Oliveira (2013), para quem a primeira está associada ao ensinar (a ação individual 
do projeto precisavam ser uma oportunidade de enriquecer a formação inicial dos licenciandos e, ao mesmo, tempo tensionar o processo formativo deles com as vivências da escola, em um diálogo e troca coletiva de experiências com as professoras regentes.

A outra razão estava presente em um pensamento exigente que fazíamos quando nos referíamos a palavras e expressões como: educação geográfica, novas maneiras de ensinar-aprender, raciocínio espacial e práticas espaciais. Tratava-se de buscar insistentemente praticar essas coisas desde a formação inicial docente e dentro do próprio projeto que desenvolvíamos. Ou seja, como seria possível praticarmos aquilo que estudávamos e discutíamos nos encontros e debates sobre as leituras? Este último elemento ganhou contornos bastante significativos a partir do diagnóstico feito com o corpo docente da escola, pois o mesmo apontou três dificuldades bem destacadas: com o livro didático e o planejamento da escola, com a linguagem e a escrita dos estudantes e as tentativas de introduzir elementos dinamizadores nas aulas visando, de fato, encontrar os alunos e conduzi-los/conduzir-se com eles no aprendizado.

\section{A questão fundamental do projeto e os sujeitos atuantes no processo}

Um foco de grande centralidade na experiência estava em duas bases que tomamos como fundamentais para a melhoria da educação pública e na efetiva promoção de uma educação geográfica: a aprendizagem e a docência. Ou seja, os sujeitos mais diretamente envolvidos no ensino-aprendizagem dos saberes geográficos estão inevitavelmente articulados nesse par, dado que as possibilidades de aprendizagem no contexto escolar - a reeducação dos sujeitos para a compreensão de suas espacialidades em bases cognitivas mais complexas - encontra-se vinculada (e não dependente) às ações do professor, que no exercício da docência precisa assumir intervenções e mediações necessárias ao desenvolvimento dos educandos.

A compreensão de aprendizagem advém de leituras e debates que hoje fundamentam a ação pedagógica e as reflexões sobre o ensino de geografia. Nesse aspecto, a principal referência sobre aprendizagem que compunha as leituras da equipe teve por base a contribuição de Vigotski e de especialistas em ensino de Geografia que tem pesquisado e refletido sobre esse tema, como Cavalcanti (1998), Castellar (2005) e Couto (2005). Desses autores, a afirmação de uma geografia escolar que tenha bases metodológicas firmes na ciência geográfica, mas também nas práticas espaciais dos alunos e na dimensão da cultura escolar, é fundamental. Dessa compreensão resulta um pensamento e atitude que possa desvendar a espacialidade cotidiana das cidades e dos lugares,

docente) enquanto a prática pedagógica seria mais complexa (práxis), relacionada a um conjunto "de aspectos sociais diversos que perpassam todo o processo de ensino-aprendizagem", portanto, sendo bem mais abrangente que a prática docente. que também fortalece as escolhas para a proposição de atividades pedagógicas com foco na aprendizagem. Nas discussões dos estudos, uma das professoras destacou o modo como a aprendizagem a partir da leitura de Vigotski (2010) a levou a compreender que a mesma deveria ter em conta a linguagem, o pensamento e a realidade no desenvolvimento dos indivíduos, bem como considerar a interferência da escola no processo.

As atividades desempenhadas nos proporcionavam percepções imediatas relativas ao ensino de Geografia, mas também transformavam aspectos da docência e da formação inicial e continuada em desafios para a nossa aprendizagem. Assim, à medida que refletíamos sobre o diagnóstico das aulas de Geografia na escola, sobre as condições em que as atividades educativas se desenvolviam, sobre a abordagem dos conteúdos e as atividades que elaboramos e praticamos, algumas novas questões se imponham para investimento futuro. Para ilustrar alguns desses aprendizados:

- O ensino médio mantido na escola da esfera municipal era indicativo de uma situação de excepcionalidade ${ }^{3}$, para atender à demanda da juventude da cidade. Além disso, colocava a incerteza permanente sobre o futuro daquele trabalho.

- O esforço de professoras de Geografia para, no contexto de suas dificuldades, inovar e criar estratégias e alternativas para a dinamização das aulas.

- A experiência profissional revista a partir da formação inicial indicava a necessidade de atualização e aperfeiçoamento. Uma necessidade dificultada pelo isolamento da cidade em relação a eventos, bem como no acesso aos cursos de aperfeiçoamento e pós-graduação das universidades públicas.

- As reuniões e encontros de áreas ocupavam espaço de reflexão, troca de experiências e aperfeiçoamento que de alguma maneira remediavam a necessidade de formação continuada.

- Os licenciandos constatavam, e enfrentavam, as exigências de transformar os conceitos e metodologias adquiridas na formação inicial em situações reais de aprendizagem com os adolescentes, ao mesmo tempo que encontravam possibilidades efetivas de criação e elaboração de materiais.

As reflexões sobre a questão da docência tiveram nas contribuições de Freire (1996) e Gadotti (2001) possibilidade de aprofundamento, assim como de reafirmação sobre a importância do trabalho docente para o desenvolvimento dos estudantes, sobre a responsabilidade do professor para geografia escolar, bem como para afirmação da autoria e função intelectual do professor na escola. As exigências à docência eram de certa

3 No Brasil a etapa de educação escolar chamada de ensino médio é responsabilidade prioritária do governo estadual e não municipal. 
forma questionadas se nos espelhávamos nas colocações de Freire (1996), para quem ensinar exige compromisso com o aluno, a consciência do inacabamento e do caráter político do ato pedagógico. Entendíamos que nosso desejo de uma educação transformadora por dentro da educação geográfica bem pode inspirar-se em Gadotti (2001), para quem “Manter a tensão dialética entre indivíduo e sociedade talvez seja o princípio básico de uma pedagogia que pretenda ser transformadora das condições humanas, de suas relações consigo mesmo, com o outro" (p. 100).

A convivência e a exposição das expectativas a cada leitura e cada história - fosse de um professor, de algum estudante ou licenciando - foi possibilitando certo entrosamento, de forma que não ficou estabelecida uma hierarquia, mas um reconhecimento das distintas expectativas, das formas potenciais de contribuição, das variadas necessidades que ali se encontravam. Assim, cada sujeito presente ao processo de investigação se convencia do potencial e da necessidade do empenho coletivo para o sucesso do projeto e para a promoção de uma educação geográfica efetivamente vivida nas atividades (leituras e oficinas). Um empenho coletivo que não foi perene, apresentando altos e baixos durante o processo. Contudo, sempre que uma atividade resultava bem, se percebia a valorização de cada aprendizado.

Entendendo-se que os sujeitos atuantes nas atividades desenvolvidas no projeto encontravam-se mobilizados em torno dos conceitos de aprendizagem e docência, essa relação ganhou contornos marcantes enquanto conduzíamos as reflexões e diálogos. Cada leitura, atividade proposta e formulada pela equipe em torno dos conteúdos curriculares da pesquisa, fazia lembrar da questão de como a atividade docente estaria favorecendo aprendizagem e como tal aprendizagem estaria desafiando e aprimorando nossa atividade docente. Isto nos dois contextos de atividades de ensino: a escola que educa o jovem e a universidade que prepara o docente. Uma roda viva impulsionante!

\section{Questões e aprendizagens no decorrer da pesquisa}

Os processos de aprendizagem desejados precisavam tratar dos conteúdos curriculares importantes na educação dos jovens ao mesmo tempo em que os estimularia a perguntar-se sobre seus lugares, a ver a novidade no cotidiano ou espantar-se com determinados processos e fatos aparentemente distantes.

Essa mesma aprendizagem, em sentido complexo e diverso, também nos levaria como professores, a encontrar sentido na atividade docente à medida que compreenderíamos, com os estudantes, as situações de mobilização e questionamentos, a formulação das ideias a partir de certo investimento em leitura, a compreensão de dada forma de relato ou linguagem em cada intervenção planejada e até mesmo adotada em um ímpeto ou improviso. Isto porque era possível esperar que as reações dos jovens diante de cada provocação inicial feita sobre os temas de estudos podiam divergir daquilo que havia sido planejado. Ou seja, nossa aprendizagem apontava inevitavelmente para a responsabilidade pedagógica, educadora da docência. E aqui se afirmava uma exigente postura: a prontidão para a reelaboração de estratégias junto com a afirmação dos objetivos pedagógicos-didáticos. Quando, em algum momento, os alunos introduziam uma informação imprevista sobre o conteúdo do encontro, ou reagia desinteressadamente, tínhamos que rever estratégias e desestabilizar as suas certezas, para assim, retomar a questão inicialmente proposta. Isto é muito diferente de improviso!

Outra aprendizagem observada se dava nas ações dos estudantes bolsistas (secundaristas e licenciandos). As leituras e convivências os colocava em contato com as decisões tomadas em torno de objetivos didáticos explícitos. Então, se observava que eles e elas iam se sensibilizando para as escolhas dos seus professores, compreendendo os processos bem além da expressão pontual, reprodutivista e específica dos conteúdos a cada aula. Algo do processo educativo se tornava consciente no seu conjunto. Igualmente, o fato de se colocarem como proponentes de uma produção, no contexto de uma pesquisa sob a chancela da universidade, os fazia reconhecer-se capaz de interpretar o mundo, a vida, e de formular estratégias de comunicar o que aprendiam. A possibilidade de vir a ser alguém que anuncia mensagens claras, capazes de interferir na atenção dos outros se tornava real. Junto a isso, outra geografia se desdobrava quando vista no cotidiano do lugar, com elementos de localização objetiva, mas também uma geografia carregada de cultura, hábitos e intencionalidades. Uma geografia que se desvendava, levando-se em conta também a produção das necessidades e urgências, fosse de sujeitos próximos ou distantes. A cidade oferecia elementos espaciais para problematizar as concepções de região, as ideias sobre o nordeste do Brasil, sobre a África e a Ásia, sobre ecossistemas múltiplos. Isto destacaremos no próximo tópico.

\section{Elementos que marcaram o processo formativo}

Pode-se começar destacando o aprendizado sobre a condição da prática docente, com ansiedades, temores e criatividade. Trata-se de reconhecer que nas noções em geral sobre o contexto das atividades escolares, que a existência de um "censo comum docente" (Santana, 2010) e de ideias pré-concebidas sobre o trabalho no magistério induzem a graves equívocos, a afirmações impertinentes e descoladas do que vive o educador. Olhando de perto, trocando-se ideias é que se tem a chance de conhecer as angústias com as limitações cotidianas, as descobertas da incompletude da formação e as exigências da práxis, mas principalmente, fomos descobrindo energia, produção e criação de alternativas, bem como a busca de companhia solidária e compromisso. 
As percepções iniciais sobre os docentes explicitaram que a equipe da escola apresentava o elemento da experiência (com regentes que possuíam vivência em distintos contextos escolares) e o potencial dos primeiros anos da carreira docente - menos de cinco anos de magistério - em uma combinação promissora ao diálogo. As marcas da longa experiência combinavam no diálogo sobre os inconformismos e incômodos com as situações das escolas, da vida do magistério e o desinteresse dos alunos. Uma situação que vivenciamos com elas e continha fragilidades e entusiasmo, mas, sobretudo ânimo pela oportunidade de uma experiência articulada com a universidade e a retomada dos estudos dentro do ambiente laboral. No campo das fragilidades tinha-se um restrito exercício da leitura e de debate entre os profissionais, bem como as dificuldades de distinção entre os conceitos geográficos e conteúdos de ensino. As professoras também nos contavam sobre as dificuldades que tinham para estabelecer critérios de avaliação e acompanhamento da aprendizagem, tomando-se tanto os conceitos geográficos quanto os pedagógicos na realização do próprio trabalho como desafiadores. Também havia limitações para observar e detectar nos estudantes uma aprendizagem para além de provas e da produção escrita. Ou seja, uma atenção aos modos de pensar dos estudantes, antes e depois das atividades das aulas de Geografia, para compreender os efeitos dessas atividades escolares.

Os elementos do diagnóstico dos professores apontaram, então, para trabalharmos em uma linha de ação que fortalecesse a capacidade docente de criar e formular alternativas e outra, que apontasse para a reinvenção na abordagem de determinados conteúdos de ensino. Aí a solicitação para que escrevessem seus resumos, resenhas, os materiais das aulas e um caderno de campo.

A articulação entre os conteúdos de ensino (região nordeste, África, Ásia e América Latina) com o cotidiano era buscada a partir das atividades sugeridas, utilizando-se dos recursos adquiridos no projeto ${ }^{4}$. Era necessário que tais conteúdos não fossem mantidos como algo a ser aprendido somente para a realização de provas e exames escolares ou de acesso à universidade. A leitura feita sobre eles, por diferentes linguagens e na observação da vida diária, precisava encher de sentido a aprendizagem dos estudantes. As oficinas com os diversos temas buscaram este objetivo.

A atenção e constatação sobre as noções pré-concebidas a respeito da região nordeste e sobre a África provocaram muitos questionamentos

\footnotetext{
4 Cada um desses conteúdos foi objeto de pelo menos uma oficina didática para o desenvolvimento do tema, que ficou sob responsabilidade de cada professora bolsista, dos licenciandos e do coordenador. Essas atividades exigiam a elaboração da proposta, a seleção e elaboração de material tendo como suporte a Sala Ambiente de Geografia destinada ao projeto e equipada com os recursos obtidos. Foram confeccionados jogos, debates a partir de audiovisuais, registros feitos pelos estudantes e discutidos em sala, bem como o uso de diversas linguagens para cada um dos assuntos. Cada atividade precisava partir de uma questão inicial e ganhar complexidade ao longo do seu desenvolvimento, exigindo-se uma produção dos estudantes para concluir.
}

nas atividades didáticas experimentadas. Para isso, tais localidades foram, primeiro, objeto de expressão das opiniões de conhecimento geral e diário sobre elas; depois, se introduziam no trabalho aspectos da região nordeste, da África e da Ásia, dados e informações de pesquisa, bem como discursos e vozes a partir daqueles lugares. Buscou-se experimentar a leitura de diversas representações sobre esses lugares em dados econômicos, locacionais, fronteiriços, literários, depoimentos diversos e submeter às dúvidas: tais lugares são de fato como pensamos que são? Aqueles que habitam neles pensam e dizem o que sobre seus lugares? As surpresas, as dúvidas e "visões a partir do outro" foram reestruturando o conhecimento sobre aqueles conteúdos. Regionalismos do Nordeste, aspectos singulares da África, Ásia e América Latina iam se reformulando à medida que os estudantes traziam informações de que na cidade as pessoas também costumavam utilizar expressões peculiares ao lugar em seu cotidiano. Na oficina sobre a região nordeste, na referência aos seus aspectos naturais, o semiárido nordestino foi comparado com elementos da vegetação de restinga encontrada na cidade, cujo solo arenoso e a presença de cactáceas indicava a ideia de que as características de um lugar não são isoladas. Igualmente, a presença de migrantes e imigrantes mostrava o fluxo entre as regiões. Em dado momento os estudantes discutiam sobre "o nordeste contido na vida da própria cidade", fosse pelas pessoas, pelas comidas ou atividades culturais dos migrantes. Ao considerarem a atividades turística e de pescado importante para a cidade, os alunos vincularam o fluxo de pessoas de tantos outros cantos do planeta entre si (como da América Latina, da Ásia ou de outros estados do país). Então, merece destaque o fato dos estudantes terem aplicado estas questões ao conhecimento sobre a própria cidade, sobre a Região dos Lagos no Rio de Janeiro. Ou seja, a interpretação e a compreensão sobre os conteúdos geográficos favoreceu o reconhecimento de preconceitos e pré-julgamentos sobre lugares e populações (Albuquerque, 2001 e 2007), como também observar a reprodução de ideias equivocadas e preconcebidas sobre os lugares - fato que, concluiu-se, precisa ficar explicitado nas aulas de geografia ${ }^{5}$.

Outro referencial importante para a equipe veio da leitura de Mignolo (2003) a partir da qual nos questionávamos sobre a origem dos saberes presentes nos currículos ou das concepções que reproduzimos (em nós e com os estudantes) sem a devida preocupação com as origens dos saberes, suas intencionalidades ou os elementos subliminares neles presentes. Esse referencial esteve presente em quase todas as provocações iniciais das oficinas e destacou-se como elemento importante para a docência, marcando a ação pedagógica.

\footnotetext{
5 Também como desdobramento resultou o aprofundamento das reflexões sobre as visões pré-concebidas a respeito da região nordeste pelos alunos, como é tratada no livro didático, bem como a região é retratada em linguagens diversas como a produção literária. Esta escolha foi desenvolvida por uma das bolsistas como trabalho final de curso, sob o pretexto de articular as noções iniciais dos alunos com a ideias contidas na literatura (no romance Tocaia Grande, de Jorge Amado).
} 
Enquanto estas compreensões se desenvolviam sobre os conteúdos, as professoras traziam para os encontros do projeto relatos sobre a mudança de disposição dos estudantes, não apenas os bolsistas da equipe, mas de suas turmas, ao se depararem com as experimentações em torno dos conteúdos e com o espaço criado na escola para as aulas de Geografia. $O$ uso de tecnologia, o fato de ter um espaço para o manuseio e criação de material pelos próprios estudantes resultava em nova atitude de prontidão para aprender e interagir. 0 efeito daquele espaço estaria envolvendo outras equipes disciplinares, promovendo diálogo e interação com a equipe de Geografia. Apesar disso, da experiência que os enriquecia, elas observavam que a resposta da gestão da escola e da secretaria de educação ainda era de desconfiança e de pouco interesse, o que estabelecia novas exigências ao seu trabalho e à sua luta.

\section{Questões ainda desafiadoras}

Tomando por orientação o foco na educação geográfica desenvolvida na escola, a experiência desse trabalho nos permitiu focar de maneira mais amiúde no tema da aprendizagem e da docência. Daquilo que aprendemos em um exercício coletivo diverso que pôs em diálogo as perspectivas da prática docente na educação básica e na universidade, dos licenciandos em formação e da equipe de estudantes de ensino médio, permanecem algumas reflexões exigentes para investimento permanente. A primeira delas nos remete a investir na compreensão de como a educação geográfica - que vem ganhando força na comunidade geográfica brasileira e latino-americana - poderá contribuir para que os processos formativos escolares de crianças e jovens visem a superação de preconceitos, favoreça a compreensão da diversidade e o respeito às culturas. A outra, ainda na afirmação do valor dessa educação geográfica: se ela deve ter relevância inclusive no debate com a geografia acadêmica, não se faz necessário dar relevância e oportunidade aos geógrafos educadores da educação básica na conformação de sua identidade docente? E claro, sem produzir outra dicotomia (geografia escolar/geografia acadêmica), que amplifique as dificuldades conceituais da ciência geográfica. Afinal, os problemas levantados (e vividos) na Geografia Escolar são também problemas da teoria da Geografia.

Sobre as condições de autoria dos geógrafos educadores, ainda nos cabe conhecer a força e as limitações dos processos formativos dos professores para que a elaboração das aulas e a criação de materiais didáticos possam, a um tempo, revelar a capacidade de produção docente e noutro, fortalecer as intervenções pedagógicas seguras e fundamentadas. Isto nos parece fundamental para a promover aprendizagens plenas de sentido ainda que vivamos a enfrentar currículos cada vez mais engessados. Por fim, permanece incompleta a tarefa de fortalecer a produção sobre a geografia que se ensina em contextos de pesquisa que articulem, cada vez mais, a universidade e a escola de educação básica - os depoimentos docentes e de licenciandos indicam um longo caminho a percorrer.

\section{Referências}

Albuquerque, D. (2007). Preconceito contra a origem geográfica e de lugar-As fronteiras da discórdia. São Paulo: Cortez.

Albuquerque, D. (2001). A Invenção do Nordeste e Outras Artes. São Paulo: Cortez.

Cavalcanti, L. (1998). Geografia, Escola e Construção de Conhecimentos. Campinas: Papirus

Castellar, S. (2005). Educação geográfica, teorias e práticas docentes. São Paulo: Contexto.

Couto, M. (2005). Pensar por conceitos geográficos. Em S. Castellar (Org.), Educação Geográfica, teorias e praticas docentes (pp. 79 - 96). São Paulo: Contexto.

Freire, P. (1996). Pedagogia da Autonomia. São Paulo: Paz e Terra.

Gadotti. M. (2001). Concepção dialética da Educação. (12ª Ed.). São Paulo: Cortez.

Mignolo, W. (2003). Histórias Locais / Projetos Globais: colonialidade, saberes subalternos e pensamento liminar. Belo Horizonte: UFMG.

Oliveira, M. (2013). Sequência didática interativa no processo de formação de professores. Rio de Janeiro: Vozes.

Santana, M. (2010). A educação geográfica escolar: conteúdos e referências docentes (tese de doutorado). Universidade de São Paulo, São Paulo, Brasil. 